\title{
Prediction of the True Stress of ZE20 Magnesium Alloy at Different Temperatures and Strain Rates
}

\author{
Sedat Bingöl1,* - Wojciech Misiolek² \\ ${ }^{1}$ Dicle University, Department of Mechanical Engineering, Turkey \\ 2 Institute for Metal Forming, Lehigh University, USA
}

Compression tests were performed to obtain flow stress curves of a newly developed magnesium ZE20 alloy for automobile applications. The experiments were performed in a temperature range from $200{ }^{\circ} \mathrm{C}$ to $425^{\circ} \mathrm{C}$ and the strain rates from 0.01 to $15 \mathrm{~s}^{-1}$ to examine the material responses at various processing conditions. Artificial neural network (ANN) and gene expressing programming (GEP) were used for the estimation of the true stress curves obtained from the experimental tests. Recently, a few studies were performed to estimate the true stress of different magnesium alloys by using ANN modelling method. However, this method has not yet been applied for the ZE20 alloy; therefore, it was the subject in this study. Furthermore, this study is the first attempt of using a GEP model to predict the true stress of a magnesium alloy. Both developed ANN and GEP models successfully predicted the true stress of ZE20 alloy.

Keywords: magnesium, ZE20, compression, true stress, GEP, ANN, prediction

Highlights

- $\quad$ The compression tests were performed to obtain the flow stress curves of a newly developed magnesium ZE20 alloy for automobile applications.

- An artificial neural network (ANN) and gene expressing programming (GEP) were used for the estimation of the true stress curves obtained from the experimental tests.

- $\quad$ Good agreement between predicted and experimental true stress results was obtained for ZE2O alloy using both ANN and GEP models.

- An equation was derived from the developed GEP model which is simple and can easily be used for further true stress predictions of the ZE2O alloy.

\section{O INTRODUCTION}

In response to increasing energy and resource consumption in the automotive industry, designers have recently become more interested in lightweight alternatives to common materials. Strong expectations exist that the automotive industry will begin using magnesium alloys in the production of numerous components due to their high strength/weight ratio.

Most magnesium products in the automotive industry are manufactured via high pressure die casting (HPDC); such products include engine blocks and heads, transmission housings, and other small components [1]. Designers are searching for new ways of building automobiles with reduced harmful environmental impact. Reducing the weight of automobiles is an important opportunity for reducing fuel consumption. Therefore, the share of wrought magnesium alloys needs to improve. Although these alloys have better mechanical properties than cast magnesium alloys, they have had limited usage until now due to deformation limitations.

In the recent literature, many studies focus on the deformation processing of wrought $\mathrm{Mg}$ alloys. $\mathrm{Li}$ et al. [2] performed compression tests to determine a basic relationship for a wrought magnesium alloy with a wide range of strain rates; the results showed that the flow curve reaches a steady state at low strain values. Mishra et al. [3] encountered an abnormal change in the behaviour of $\mathrm{Mg}$ due to the addition of $\mathrm{Ce}$. Luo et al. [4] studied high ductility magnesium-zinc-cerium extrusion alloys. Their studies showed that by adding a small amount of zinc, the strength of the Mg-Ce alloy can be improved notably. Luo et al. [5] also examined the microstructure and mechanical properties of extruded magnesium alloy tubes; the results revealed that the mechanical properties can be improved with the addition of $\mathrm{Ce}$ to pure magnesium. Chino et al. [6] investigated the compressive properties of $\mathrm{Mg}$ alloys from room temperature up to $500{ }^{\circ} \mathrm{C}$ to understand the effects of $\mathrm{Ce}$ on the deformation process; the results showed that the addition of $\mathrm{Ce}$ increased the ductility of $\mathrm{Mg}$ alloy at room temperature, but decreased it at $300^{\circ} \mathrm{C}$. El-Morsy et al. [7] investigated the microstructural evolution of AZ61. They achieved fine grain size via a combination of hot extrusion and thermomechanical processing.

In light of the literature survey, it can be said that a significant part of the current research and development projects on magnesium alloys and their 
use in the automotive industry is generally focused on wrought magnesium alloys. The reason for this is the fact that the average usage of magnesium alloys in automobiles today is low and, therefore, there is great potential for its increase.

The prediction of metal behaviour based on nature-inspired computational techniques, such as artificial neural networks (ANN), are attracting considerable interest from researchers. ANNs offer a good and fast alternative to conventional methods for predictive modelling [8] and [9]. Regarding the application of ANN modelling to metal forming, $\mathrm{Li}$ et al. [10] showed that ANNs can be used to predict the tensile strength of extrusion tubes. Zhou et al. [11] used ANN to predict the extrusion load and exit temperature for AZ31B magnesium alloy. Bingol et al.
[12] predicted the extrusion load of gear like profiles for different extrusion dies by ANN. Ayer et al. [13] performed an ANN modelling for lateral extrusion load estimation. The results they obtained were in good agreement with the experimental results. Toros and Ozturk [14] developed an ANN modelling to analyze the material flow curves of strain-hardened magnesium alloys. Sabokpa et al. [15] suggested an ANN model for the prediction of the flow behaviour of AZ81 magnesium alloy. In another study, Qin et al. [16] predicted the deformation behaviour of ZK60 by ANN. Djavanroodi et al. [17] successfully used ANN modelling for die design in equal-channel angular pressing.

Another artificial intelligence (AI) technique, gene-expressing programming, which is a new

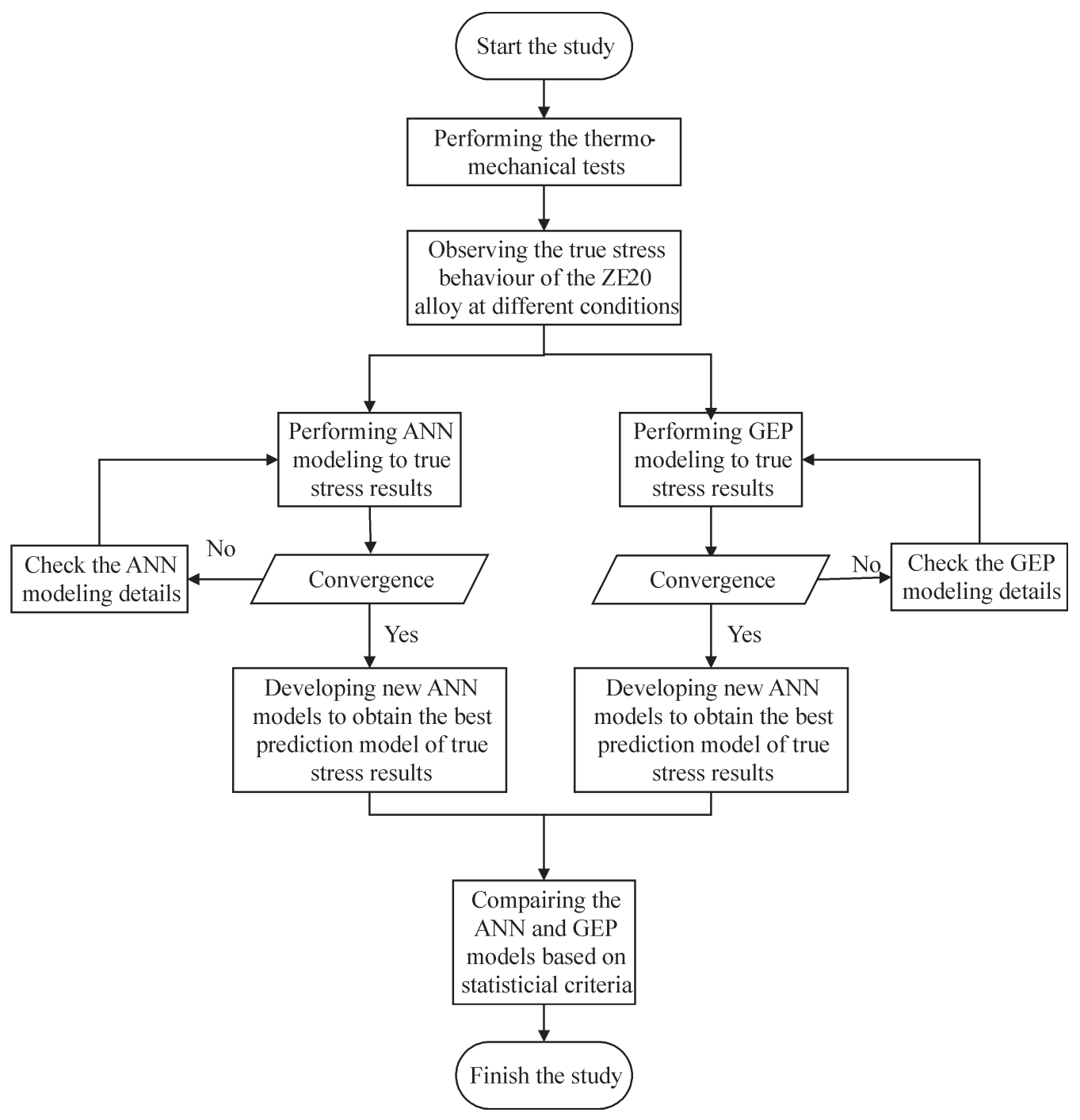

Fig. 1. Framework of this study 
evolutionary algorithm developed by Ferreira [18], has been used in different engineering areas [19]. Several gene-expressing programming (GEP) approaches have been conducted and reported in the literature, but it is important to note that a predictive GEP model for the deformation behaviour of a magnesium alloy has not been reported in literature and is the subject of this study. In the current study, the formability of the ZE20 magnesium alloy, which was recently developed by General Motors [4] and [5], was studied. After compression tests of the alloy, the ANN and GEP models were developed to predict the true stress curves of the alloy. The capability of the developed models has been evaluated using statistical measurement criteria such as the coefficient of determination $\left(\mathrm{R}^{2}\right)$, mean square error (MSE) and mean absolute error (MAE).

\section{METHODOLOGY}

The study was conducted in two phases: in the first, the thermo-mechanical tests were performed to obtain the flow stress curves for ZE20 magnesium alloy. In the second, the ANN and GEP models were developed to predict the true stress curves of ZE20 alloy. Finally, the best ANN and GEP models developed have been compared. The framework of the study can be seen in Fig. 1.

\subsection{Experimental Study}

A new magnesium alloy, ZE20 (Mg -2 wt. $\% \mathrm{Zn}-0.2$ wt.\% $\mathrm{Ce}$ ), was deformed to observe the resulting true stress behaviour. The detailed results of the physical modelling are reported in the literature [20]. The accuracy of the ANN and GEP models performed in this part of the study depends strictly on the quality of the input data regarding the physical properties of the material. To build the ANN and GEP models of the ZE20 alloy, the data on true stress versus temperature, true strain, and strain rate have to be introduced into the models. To obtain these data for the performed study, uniaxial compression tests were performed at temperatures of $200{ }^{\circ} \mathrm{C}, 375^{\circ} \mathrm{C}$ and $425^{\circ} \mathrm{C}$ and strain rates of $0.01 \mathrm{~s}^{-1}, 5 \mathrm{~s}^{-1}$ and $15 \mathrm{~s}^{-1}$. The experiments for the hot workability analysis were conducted on a Gleeble 3500 using the specimens with a diameter of $8 \mathrm{~mm}$ and a height of $12 \mathrm{~mm}$.

\subsection{Development of ANN Model}

ANN is a computational structure made up of a number of simple, highly interconnected processing elements that can learn from observing data sets. ANNs can capture many types of relationships that otherwise may have been very challenging to explain. Therefore, researchers attempted to apply ANN to some complicated engineering problems. ANNs have three layers that are interconnected. The first layer is made up of a set of input nodes that contain an activation function. Those nodes transfer data to the second layer which in turn sends the outputs to the third layer. Neurons in each layer behave as independent processing elements. After training the network using a special learning function, a set of data that has not been trained is used for the testing and validation of the networks. This process is repeated until a minimal error in the entire procedure is obtained [21]. Different learning rules can be used in order to improve the ANNs' performance. Back propagation is a common algorithm for training the ANNs since it has the advantages of being very simple and accurate. After the network is initialized with random weights, the method updates the weights to match the required output. Weight updating repeats until the loss function is minimized.

This study takes into consideration three input parameters: two of them, temperature and strain rate, represent the compression test conditions and one of them, true strain $(\varepsilon)$, represents the result of the true stress for each temperature $(T)$ and strain rate $(\dot{\varepsilon})$. The output layer consists of one neuron, which represents the true stress of the ZE20 alloy. A transfer function is required to translate the input signals to output signals. In this study, a TanhAxon transfer function was used to introduce nonlinearity into the network. An ANN structure with feed-forward neural networks was used for estimating the true stress of the ZE20 alloy in compression tests. The total experimental data (657 samples) was randomized and divided into two categories, named training subsets $(80 \%)$ and testing subsets $(20 \%)$. The ideal transfer function and the number of neurons and hidden layers should be found through a trial-and-error method. In the selection of best network structure, measurements ( $\mathrm{R}^{2}$, RMSE, MAE) were used as the performance criteria between the ANN predicted and the experimental true stress of ZE20. After several trials of the ANN structure, the optimal neural network structure was determined with the Levenberg-Marquardt back-propagation algorithm, TanhAxon transfer function, and 6 neurons in one hidden layer. Fig. 2 shows the structure of the feed-forward ANN model used. 


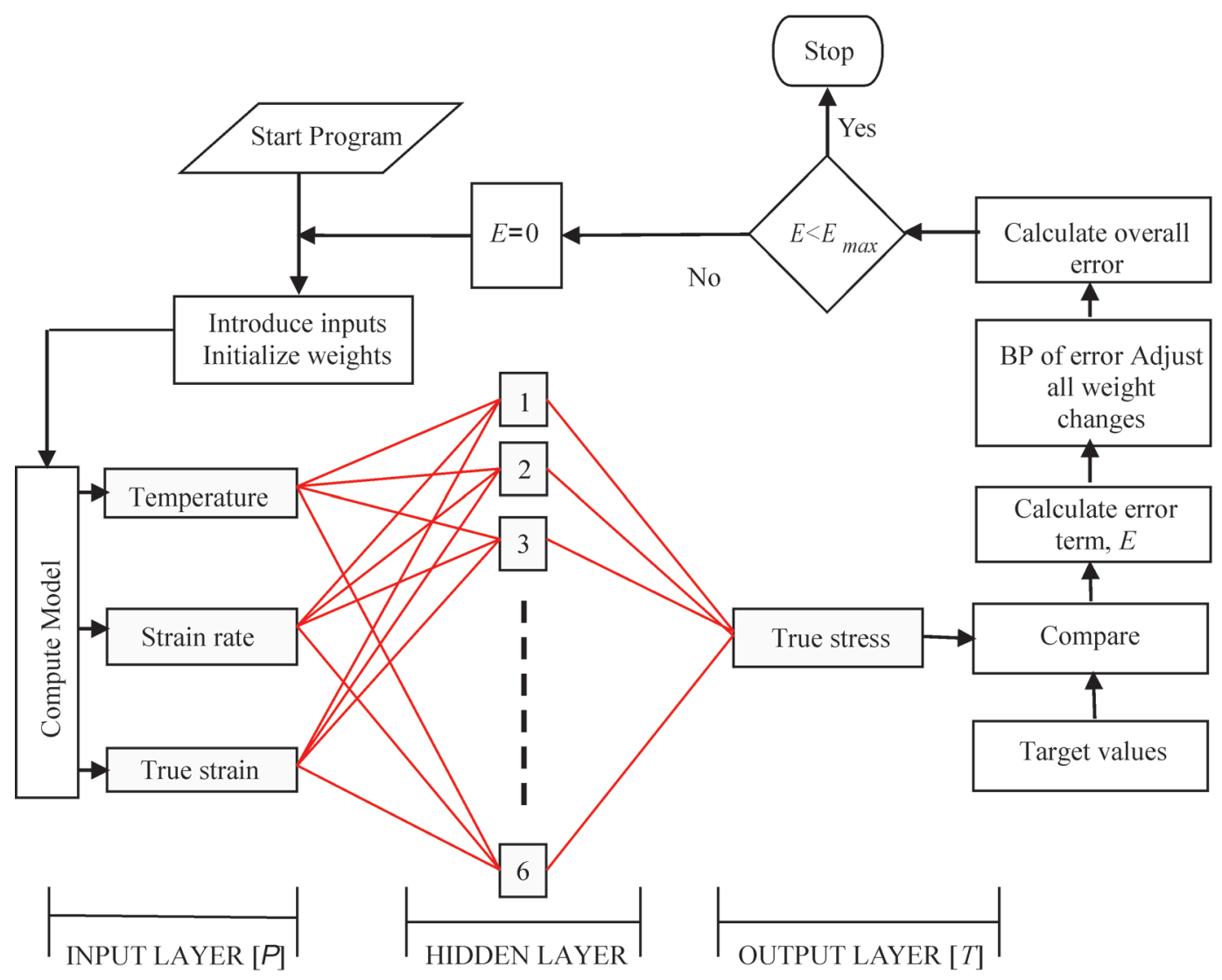

Fig. 2. Framework of this study

\subsection{Development of GEP Model}

Another AI technique, GEP, which is also used in this study, is an evolutionary algorithm that is capable of discovering functions from large data sets by evolving computer programs. These programs act much like a living organism. They can learn and adapt by changing their sizes and shapes. Evolution of the population takes place after selecting a population of individual by means of the genetic operators. Once a satisfactory fitness level is achieved, the algorithm terminates. The predicted values are compared with the actual ones until a minimal error is obtained. This process is repeated until an acceptable solution is achieved. There are two major elements of GEP: expression trees (ETs) and chromosomes. The chromosome symbolizes a mathematical expression and contains one or more genes. These genes consist of two components, the tail, and the head. After converting each chromosome into an ET, a mathematical equation is derived.
Table 1. Parameters of the optimized GEP model

\begin{tabular}{|c|c|c|}
\hline Parameter & Description of parameter & Setting of parameter \\
\hline$P_{1}$ & Chromosomes & 30 \\
\hline $\mathrm{P}_{2}$ & Fitness function error type & RRSE \\
\hline $\mathrm{P}_{3}$ & Number of the genes & 3 \\
\hline $\mathrm{P}_{4}$ & Head size & 7 \\
\hline $\mathrm{P}_{5}$ & Linking function & + \\
\hline$P_{6}$ & Function set & $\begin{array}{c}+,-, \times, /, \sqrt{ }, \underline{x}^{2}, x^{3}, x^{1 / 3} \\
\ln , 1 / x\end{array}$ \\
\hline $\mathrm{P}_{7}$ & Mutation rate & 0.044 \\
\hline $\mathrm{P}_{8}$ & $\begin{array}{l}\text { One-point recombination } \\
\text { rate }\end{array}$ & 0.3 \\
\hline$P_{9}$ & $\begin{array}{l}\text { Two-point recombination } \\
\text { rate }\end{array}$ & 0.3 \\
\hline$P_{10}$ & Inversion rate & 0.1 \\
\hline$P_{11}$ & Transposition rate & 0.1 \\
\hline
\end{tabular}

The aim of GEP models performed in this study was to develop a mathematical formulation that predicts the true stress of ZE20 alloy. The input parameters and the total data used for the developed GEP models were the same as the ones used in the 
ANN models. Different numbers of chromosomes, genes, and head sizes affect the performance of the GEP model. Therefore, their number was varied to obtain the ideal GEP model. The number of chromosomes was varied between 10 and 40, the number of genes between 2 and 7 and the head sizes between 5 and 9. Parameters of the ideal GEP model can be seen in Table 1 .

Furthermore, true stress prediction equations for the best GEP model were obtained.

Fig. 3 shows the ET of the formulation of the true stress, which is:

$$
\begin{aligned}
\text { dblTemp }= & ((((d[0] \times d[2])-\operatorname{pow}(\mathrm{G} 1 \mathrm{c} 0,3))- \\
& -(\mathrm{G} 1 \mathrm{c} 1 / d[0])) \times d[2]) ; \\
\text { dblTemp }+= & (\mathrm{G} 2 \mathrm{c} 0-((\operatorname{pow}(\mathrm{G} 2 \mathrm{c} 1,3)+ \\
& +(d[1]+\mathrm{G} 2 \mathrm{c} 0)) \times d[2])) ; \\
\text { dblTemp }+= & (\mathrm{G} 3 \mathrm{c} 1 \times((\log (d[0])+ \\
& +(d[0]+\mathrm{G} 3 \mathrm{c} 0))-(d[2] \times d[1]))) ;
\end{aligned}
$$

The real parameters in the derived GEP formulation are $d[0]=\dot{\varepsilon}, d[1]=T$ and $d[2]=\varepsilon$. Constants and coefficients in the Eq. (1) are G1c0 $=-9.568298$, $\mathrm{G} 1 \mathrm{c} 1=2.070037, \mathrm{G} 2 \mathrm{c} 0=9.993287, \mathrm{G} 2 \mathrm{c} 1=8.020996$, $\mathrm{G} 3 \mathrm{c} 0=9.602448$ and $\mathrm{G} 3 \mathrm{c} 1=1.652527$. After placing the real values, the equation becomes:

$$
\begin{aligned}
& \sigma=\left(\dot{\varepsilon} \varepsilon+9.57^{3}-\frac{2.07}{\dot{\varepsilon}}\right) \varepsilon+9.99- \\
& -\left(-8.02^{3}+T+9.99\right) \varepsilon+1.65(\ln \dot{\varepsilon}+\dot{\varepsilon}+9.6-\varepsilon T) .
\end{aligned}
$$

\begin{tabular}{|c|c|c|c|c|c|}
\hline GEP Models & Linking Function & Mathematical functions & RMSE & MAE & $\mathrm{R}^{2}$ \\
\hline M1 & Addition & $+,-, \times, /, \sqrt{ }, x^{2}, X^{3}, x^{1 / 3}, \ln$ & 22.52 & 19.14 & 0.98 \\
\hline M2 & Addition & $+,-, \times, /, \sqrt{ }, x^{2}, x^{3}, x^{1 / 3}, 1 / x$ & 17.43 & 14.68 & 0.99 \\
\hline M3 & Addition & $+,-, \times, /, \sqrt{ }, x^{2}, x^{3}, x^{1 / 3}, \ln , 1 / x,(-x)$ & 21.71 & 17.18 & 0.98 \\
\hline M4 & Addition & $+,-, \times, /, \sqrt{ }, x^{2}, x^{3}, x^{1 / 3}, \ln , 1 / x$, abs & 34.04 & 25.52 & 0.96 \\
\hline M5 & Addition & $+,-, \times, /, \sqrt{ }, x^{2}, x^{3}, x^{4}, x^{1 / 4}, x^{1 / 3}, \ln , 1 / x$ & 12.68 & 10.08 & 0.99 \\
\hline M6 & Addition & $+,-, \times, /, \sqrt{ }, x^{2}, x^{3}, x^{1 / 3}, \operatorname{In}, \exp$ & 15.42 & 11.14 & 0.99 \\
\hline M8 & Addition & $+,-, \times, /, \sqrt{ }, x^{2}, x^{3}, x^{1 / 3}, \ln , \exp , 1 / x, \log$ & 47.25 & 32.99 & 0.93 \\
\hline M9 & Addition & $+,-, \times, /, \sqrt{ }, x^{2}, x^{3}, x^{1 / 3}, \ln , 1 / x$ & 8.48 & 6.81 & 0.99 \\
\hline M10 & Multiplication & $+,-, \times, /, \sqrt{ }, x^{2}, x^{3}, x^{1 / 3}, \ln , 1 / x$ & 17.3 & 12.13 & 0.99 \\
\hline ANN Models & Algorithm & Transfer function $\quad$ Structure & RMSE & MAE & $\mathrm{R}^{2}$ \\
\hline M1 & LM & TanhAxon & 3.12 & 2.17 & 0.99 \\
\hline M2 & Momentum & TanhAxon & 26.24 & 20.73 & 0.95 \\
\hline M3 & LM & Sigmoid & 18.09 & 6.17 & 0.97 \\
\hline M4 & Momentum & Sigmoid & 100.31 & 77.84 & 0.68 \\
\hline M5 & LM & TanhAxon & 14.91 & 3.25 & 0.98 \\
\hline
\end{tabular}
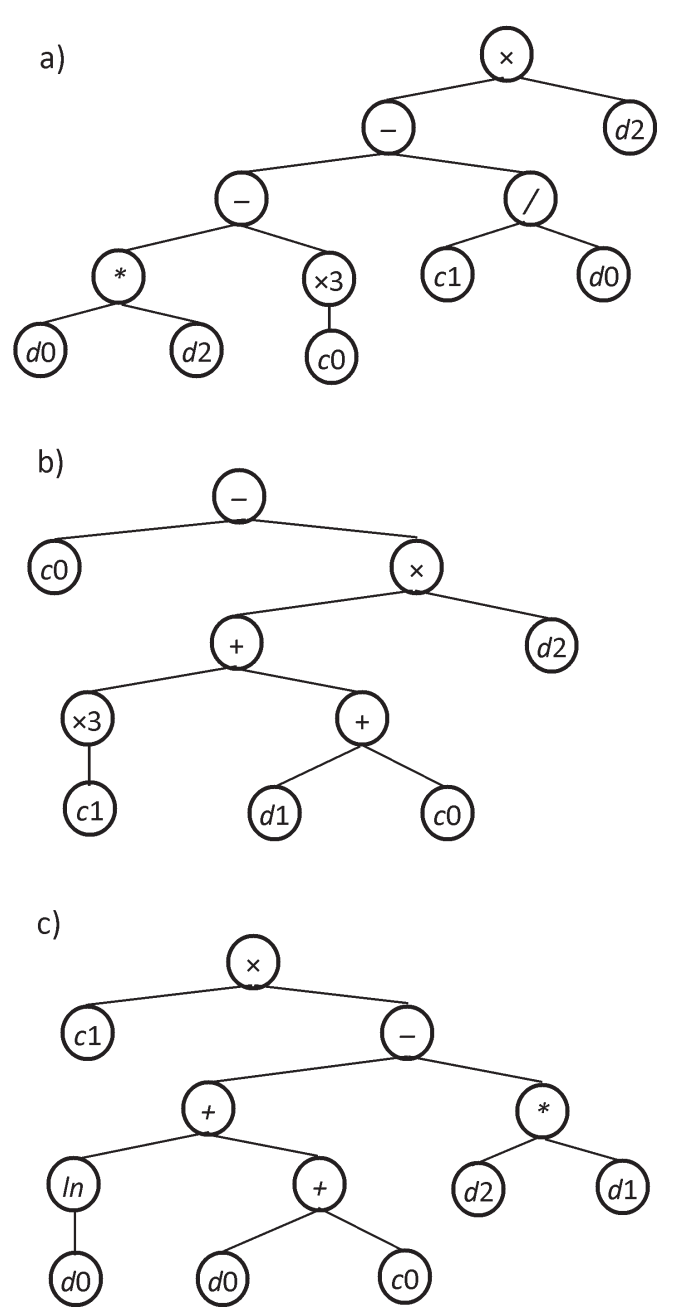

Fig. 3. Expression tree (ET) with three genes of the best GEP model (Model 9); a) sub-ET 1, b) sub-ET 2, and c) sub-ET 3

Table 2. Performed GEP (with different mathematical and linking functions) and ANN models for the prediction of true stress of ZE20 alloy 


\section{RESULTS AND DISCUSSION}

Fig. 4 shows the true stress vs the true strain curves for the ZE20 alloy. The temperatures were selected as $200{ }^{\circ} \mathrm{C}, 375{ }^{\circ} \mathrm{C}$, and $425{ }^{\circ} \mathrm{C}$, and the strain rates
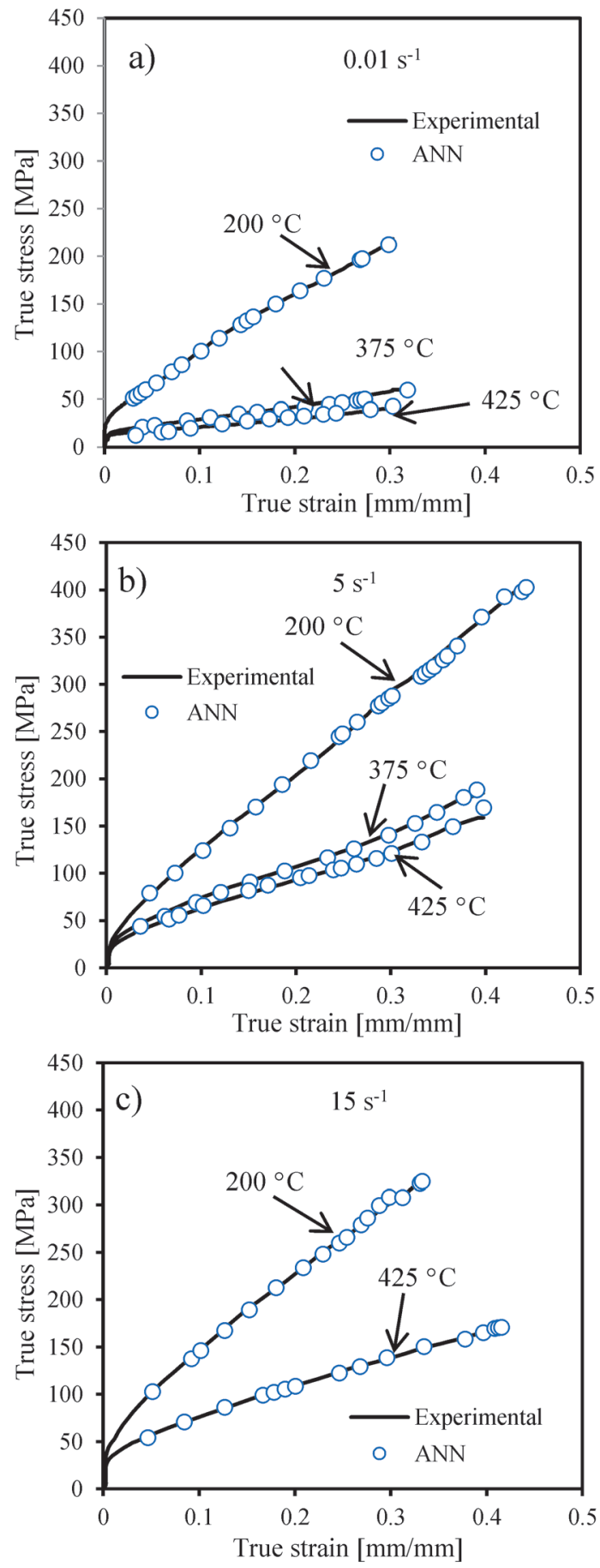

were selected as $0.01 \mathrm{~s}^{-1}, 5 \mathrm{~s}^{-1}$, and $15 \mathrm{~s}^{-1}$. It is well known that while the strain rate is increasing during forming, higher stress is required to deform material to the same strain. The integral of the flow stress diagram represents input energy and the term energy
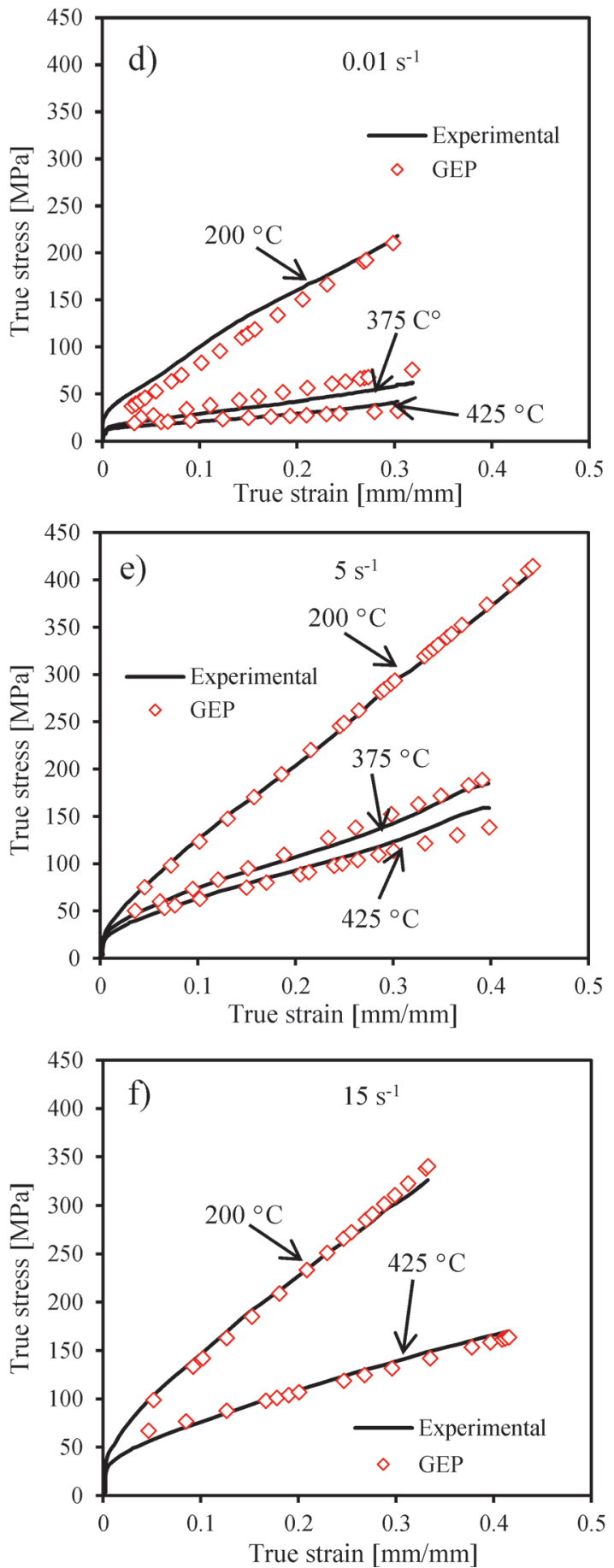

Fig. 4. Comparison between predicted (with ANN and GEP) and experimental true stress; $a, b$ and c) experimental vs ANN at $0.01 s^{-1}, 5 s^{-1}$ and $15 \mathrm{~s}^{-1}$, respectively, $d$, e and f) experimental vs GEP at $0.01 \mathrm{~s}^{-1}, 5 \mathrm{~s}^{-1}$ and $15 \mathrm{~s}^{-1}$, respectively 
is inversely dependent on time. More energy is needed to complete the same amount of deformation for a shorter time. It can be seen from Fig. 4 that the true stress increases with increasing strain rate at a true strain value. However, it must be noted that higher maximum true strain values occurred at lower strain rates. This demonstrates the dependence of material ductility on strain rate. Contrary to strain rate, the necessary deformation stress decreases with increasing temperature.

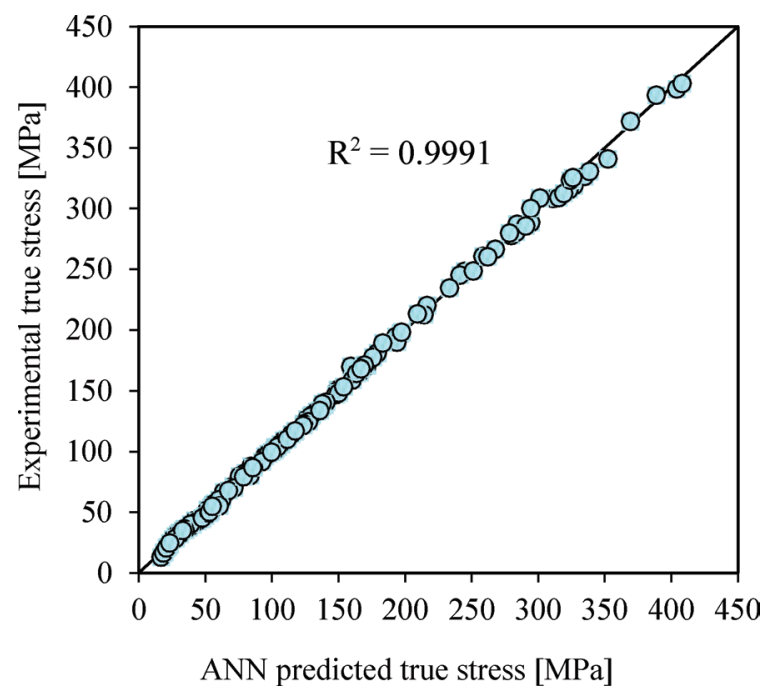

Fig. 5. Comparison between ANN predicted and experimental true stress of ZE20

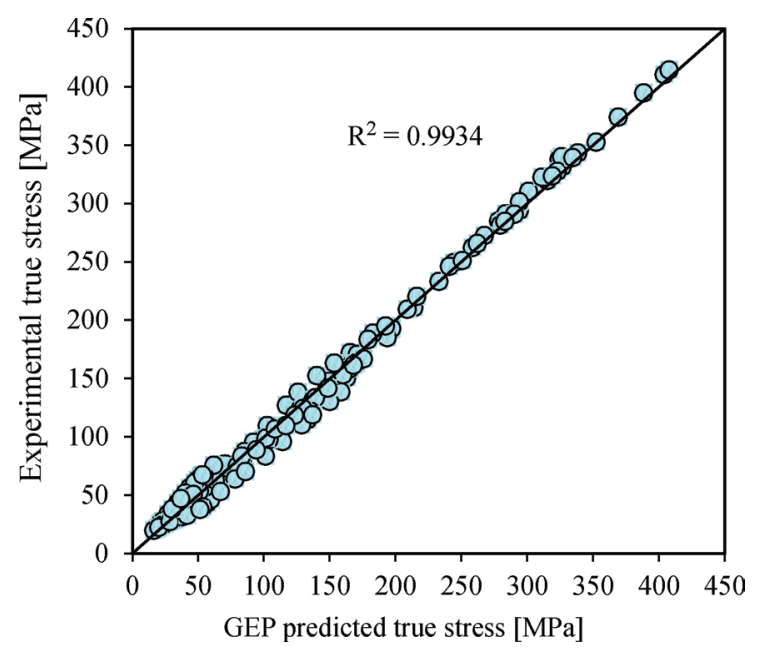

Fig. 6. Comparison between GEP predicted and experimental true stress of ZE20

The accuracy of the developed ANN and GEP models to predict the results of the compressions tests was evaluated using statistical measurement criteria ( $\left.\mathrm{R}^{2}, \mathrm{MSE}, \mathrm{MAE}\right)$, which can be seen in Table 2. Both models' predictions do match well with the experimental results. It is accepted that an obtained result of $\mathrm{R}>0.8$ with the prediction model indicates that the estimated results agree well with the measured values [22]. In this study, higher values of $\mathrm{R}^{2}$ were obtained by a number of developed GEP and ANN models. Among them, the best GEP model is Model 9, while the best ANN model is Model 1 (See Table 2). A very high $\mathrm{R}^{2}$ value (approximately 0.99 ) was obtained by these two models. Taking the other performance criteria into consideration, RMSE of $3.12 \mathrm{MPa}$ and 8.48 MPa, and MAE of 2.17 MPa and 6.81 MPa were obtained for the developed ANN (Model 1) and GEP (Model 9) models, respectively. These reasonable results show that the developed models are efficient to be used to predict the true stress of the ZE20 alloy. Fig. 4 also graphically compares the experimental true stress with the best ANN and GEP predicted true stresses. As previously mentioned, the higher $\mathrm{R}^{2}$ and lover MAE and RMSE give better agreement between the actual and the predicted results. In this respect, it can be seen from Table 2 that the developed ANN model is slightly better than the developed GEP model at predicting the true stress of the ZE20 alloy. Figs. 5 and 6 also support the results seen in Table 2 that the deviations around the regression lines are smaller for the ANN models.

\section{CONCLUSIONS}

Compression tests of ZE20 magnesium alloy were performed under different deformation conditions using a Gleeble thermo-mechanical simulator. The results of the experimental tests were used to develop the best ANN and the GEP model. The conclusions were summarized as follows:

- Good agreement between predicted and experimental true stress results were obtained for a ZE20 alloy using both ANN and GEP models in terms of higher $\mathrm{R}^{2}$ and lower RMSE and MAE values. $\mathrm{R}^{2}$ of 0.99 and 0.99 , RMSE of $3.12 \mathrm{MPa}$ and $8.48 \mathrm{MPa}$, and MAE of $2.17 \mathrm{MPa}$ and 6.81 MPa were obtained for the developed best ANN and GEP models, respectively

- The derived equation by the developed GEP model in this study is simple and can easily be used for further true stress predictions of the ZE20 alloy.

- The GEP model was capable of estimating the true stress of ZE20 magnesium alloy with high accuracy. However, the developed ANN model was slightly more successful than the GEP model. 


\section{ACKNOWLEDGEMENTS}

The authors would like to acknowledge the partial financial support for this study from the United States Automotive Materials Partnership (cooperative agreement 07-1864). The authors would also like to thank The Scientific and Technological Research Council of Turkey for supporting the visit to Lehigh University and appreciate the financial support of the Loewy Family Foundation through the Loewy Professorship at Lehigh University.

This material is based in part upon work supported by the Department of Energy National Energy Technology Laboratory under Award Number DE-EE0003583. This report was prepared as an account of work sponsored by an agency of the United States Government.

\section{REFERENCES}

[1] Zhang, H., Yan, Q., Li, L. (2008). Microstructures and tensile properties of AZ31 magnesium alloy by continuous extrusion forming process. Materials Science and Engineering: $A$, vol. 486, no. 1-2, p.295-299, Dol:10.1016/j.msea.2007.09.001.

[2] Li, L., Zhou, J., Duszczyk, J. (2006). Determination of a constitutive relationship for AZ31B magnesium alloy and validation through comparison between simulated and real extrusion. Journal of Materials Processing Technology, vol. 172, no. 3, p. 372-380, D0l:10.1016/J.msea.2007.09.001.

[3] Mishra, R.K., Gupta, A.K., Rao, P.R., Sachdev, A.K., Kumar, A.M., Luo, A.A. (2008). Influence of cerium on the texture and ductility of magnesium extrusions. Scripta Materialia, vol. 59, no. 5, p. 562-565, D0l:10.1016/j.scriptamat.2008.05.019.

[4] Luo, A.A., Mishra, R.K., Sachdev, A.K. (2011). Highductility magnesium-zinc-cerium extrusion alloys. Scripta Materialia, vol. 64, no. 5, p. 410-413, D0l:10.1016/j. scriptamat.2010.10.045.

[5] Luo, A.A., Wu, W., Mishra, R.K., Jin, L., Sachdev, A.K., Ding, W. (2010). Microstructure and mechanical properties of extruded magnesium-aluminum-cerium alloy tubes. Metallurgical and Materials Transactions A, vol. 41, no. 10, p. 2662-2674, D0I:10.1007/s11661-010-0278-3.

[6] Chino, Y., Kado, M., Mabuchi, M. (2008). Compressive deformation behaviour at room temperature $-773 \mathrm{~K}$ in $\mathrm{Mg}$ 0.2 mass \% (0.035 at. \%) Ce alloy. Acta Materialia, vol. 56, no. 3, p. 387-394, D0l:10.1016/j.actamat.2007.09.036.

[7] El-Morsy, A., Ismail, A., Waly, M. (2008). Microstructural and mechanical properties evolution of magnesium AZ61 alloy processed through a combination of extrusion and thermomechanical processes. Materials Science and Engineering: A, vol. 486, no. 1-2, p. 528-533, D0l:10.1016/j. actamat.2007.09.036.

[8] Hagan, M.T., Demuth, H.B., Beale, M.H. (1996). Neural Network Design. PWS Publishing, Boston.
[9] Patterson, D.W. (1995). Artificial Neural Network Theory and Application. Prentice Hall, New York.

[10] Li, L., Zhang, H., Zhou, J., Duszczyk, J., Li, G.Y., Zhong, Z.H. (2008). Numerical and experimental study on the extrusion through a porthole dies to produce a hollow magnesium profile with longitudinal weld seams. Materials \& Design, vol. 29, no. 6, p. 1190-1198, D0l:10.1007/s00521-013-1532-6.

[11] Zhou, J., Li, L., Mo, J., Zhou, J., Duszczyk, J. (2010). Prediction of the extrusion load and exit temperature using artificial neural networks based on FEM simulation. Key Engineering Materials, vol. 424, p. 241-248, Dol:10.4028/www.scientific. net/KEM.424.241.

[12] Bingol, S., Ayer, O., Altinbalik, T. (2015). Extrusion load prediction of gear-like profile for different die geometries using ANN and FEM with experimental verification. The International Journal of Advanced Manufacturing Technology, vol. 76, no. 5, p. 983-992, Dol:10.1007/s00170-014-6328-z.

[13] Ayer, O., Bingol, S., Altinbalik, T. (2015). Artificial neural network modelling of injection upsetting load. Applied Mechanics and Materials, vol. 729, p. 155-160, D0I:10.4028/ www.scientific.net/AMM.729.155.

[14] Toros, S., Ozturk, F. (2011). Flow curve prediction of Al-Mg alloys under warm forming conditions at various strain rates by ANN. Applied Soft Computing, vol. 11, no. 2, p. 1891-1898, D0I:10.1016/j.asoc.2010.06.004.

[15] Sabokpa, O., Zarei-Hanzaki, A., Abedi, H.R., Haghdadi, N. (2012). Artificial neural network modelling to predict the high temperature flow behaviour of an AZ81 magnesium alloy. Materials and Design, vol. 39, p. 390-396, D0l:10.1016/j. matdes.2012.03.002.

[16] Qin, Y.J., Pan, Q.L., He, Y.B., Li, W.B., Liu, X.Y., Fan, X. (2010). Artificial neural network modelling to evaluate and predict the deformation behaviour of ZK60 magnesium alloy during hot compression. Materials and Manufacturing Processes, vol. 25, no. 7, p. 539-545, DOI:10.1080/10426910903124894.

[17] Djavanroodi, F., Omranpour, B., Sedighi, M. (2013). Artificial Neural Network Modeling of ECAP Process. Materials and Manufacturing Processes, vol. 28, no. 3, p. 276-281, DOl:10.1080/10426914.2012.667889.

[18] Ferreira, C. (2011). Gene expression programming: A new adaptive algorithm for solving problems. Complex Systems, vol. 13, no. 2, p. 87-129.

[19] Dikmen, E. (2014). Gene expression programming strategy for estimation performance of $\mathrm{LiBr}-\mathrm{H} 2 \mathrm{O}$ absorption cooling system. Neural Computing and Applications, vol. 26, no. 2, p. 409-415, DOI:10.1007/s00521-014-1723-9.

[20] Thome, A.J., Misiolek, W.Z., Luo, A.A. (2012). Workability evaluation of new Mg-Zn-Ce alloys. 9th International Conference on Magnesium Alloys and Their Applications, Poole, W.J., Kainer, K.U. (eds.), p. 703-708.

[21] Patterson, J.M. (1997). Introduction to Artificial Neural Systems, $2^{\text {nd }}$ ed. Jaico Publishing House, New Delhi.

[22] Smith, G.N. (1986). Probability and Statistics in Civil Engineering, Collins, London. 